\title{
Student Perceptions of a Modified Flipped Classroom Model for Accreditation in a Pharmacotherapeutics Course
}

\author{
Asser Ghoneim ${ }^{1,2 *}$, Abdalla El-Lakany ${ }^{3}$ \\ ${ }^{1}$ Department of Pharmacology and Toxicology, Faculty of Pharmacy, Damanhour University, Damanhour, Egypt. \\ ${ }^{2}$ Department of Pharmacology and Therapeutics, Faculty of Pharmacy, Beirut Arab University, Beirut, Lebanon. \\ ${ }^{3}$ Department of Pharmaceutical Sciences, Faculty of Pharmacy, Beirut Arab University, Beirut, Lebanon.
}

\begin{tabular}{l} 
ARTICLE INFO \\
\hline Article history: \\
Received on: $23 / 07 / 2017$ \\
Accepted on: 18/10/2017 \\
Available online: $30 / 11 / 2017$ \\
\hline Key words: \\
Flipped classroom; \\
pharmacotherapeutics; \\
pharmacy database; student \\
perceptions; competency; \\
accreditation.
\end{tabular}

\begin{abstract}
The flipped classroom (FC) educational model, with specific modifications, may better prepare pharmacy students to acquire many of their missing key competencies. A modified partially-flipped pharmacotherapeutics classroom with pre-class-based online access to a comprehensive pharmacy education database was adopted to evaluate its impact on promoting student perceptions and to cope with international accreditation requirements. The teaching paradigm "partially-flipped" consisted of a pre-class orientation where groups of students were provided with different topics and an exclusive pharmacy database access, with no passive instructor-based prerecorded lectures. In-class time included didactic instructor-based conventional lectures about foundational curricular topics, followed by flipped student-presentations about the rest of topics. Student perceptions were collected through end-of-course evaluation forms and voluntary narrative feedback. Students were satisfied with the availability of different updated original pharmacotherapy resources and the acquisition of critical thinking, information-researching, and peers-education competencies. However, they were dissatisfied with the presentations quality of some of their peers, and the overloaded content of numerous topics included in the summative assessments. In conclusion, this qualitative study addressed some accreditation competencies that were successfully perceived as promoted student satisfaction, engagement, and raised proficiency. This might help implementing a pharmacotherapeutics competency-based framework more specific to the region using such inquiry-based blended learning approach.
\end{abstract}

\section{INTRODUCTION}

According to an earlier report from the Institute of Medicine, health care professionals are still lacking several key healthcare competencies required to meet the needs of the

\footnotetext{
* Corresponding Author

Dr. Asser I. Ghoneim, Vice-Dean (community), Faculty of Pharmacy, Damanhour University, Damanhour, Egypt.
}

Visiting Professor (2016), Department of Pharmacology and Therapeutics, Faculty of Pharmacy, Beirut Arab University, Beirut, Lebanon.

Department of Pharmacology and Toxicology (Head) and Vice-Dean (community 2016), Faculty of Pharmacy, Damanhour University, Damanhour, Egypt.E-mail(s): asser @ damanhour.edu.eg; aighoneim40@gmail.com communities they serve (IOM, 2001). These key competencies included: translating evidence into practice, utilization of technology for better patient care, inter-professional collaboration, and improving relationships; all thought to be at the core of higher education (Hawks, 2014). Colleges and universities with health care programs have been challenged to better prepare their students to meet the rapidly changing world of health care information and the complex needs of the society. Little has changed, however, in instructional delivery methods in the classroom, which raises the need to reflect on adult learning theories and methodologies (Taylor and Hamdy, 2013). One such theory to investigate is active learning. Active learning is a process where students are engaged in activities such as reading, writing, problem solving, and discussion that stimulate higher critical thinking skills such as analysis, synthesis, and evaluation. 
Active learning strategies foster students' commitment and reflection, while motivating them gain knowledge and improve skills and attitudes. Moreover, active learning helps giving essential feedback to both the student and the educator (McLaughlin et al., 2014). Particularly, a potential active learning methodology to investigate is the flipped learning model. Flipped learning moves didactic instruction, which uses lower critical thinking skills, to outside the classroom. Flipped instruction, often in the form of pre-recorded lectures, videos, and other resources, takes place prior to class time. Because didactic instruction often requires less interpretation and critical thinking, students are able to process the information on their own and come to class with a basic foundation of the material. This frees the instructor to introduce higher levels of critical thinking such as interactive, group-based, problem-solving strategies inside the classroom. This student-centered model enables each student to control content acquisition in a self-paced manner and provides more face-to-face time with the instructor when students apply higher level critical thinking skills. It also empowers student's critical cognitive development and promotes innovation through collaboration with his/her peers and the instructor. In addition, the FC can be used to fill the gap between didactic teaching and professional experiential practice, and to blend eLearning and classroom training. As a common feature of the FC, inquiry-based learning represents also an important constructivist indicator of active learning (Hawks, 2014; Jacot et al., 2014; McLaughlin et al., 2014). Nevertheless, students, at least to some degree, are initially resistant to new teaching methods and are similarly resistant to the FC methodology. When comparing student performance between FC courses and traditional courses, students in inquiry-based FC courses performed modestly better (Pierce and Fox, 2012). Frequently addressed concerns for FC included quality of audio/video pre-recorded lectures, their length, ease of platform use, and some in-class activities. The success of a FC may need to be adopted for certain best-suited courses or topics, or where there may be time constraints to the student or the instructor (Gross et al., 2015; Khanova et al. 2015; Wong et al., 2014). Furthermore, while some students complained of the time required completing pre-class preparation in courses using text-based online materials, results demonstrated thatthe increased pre-class preparation time improves the FC outcomes, as measured by exam marks (Gross et al., 2015; Khanova et al., 2015a; Khanova et al., 2015b). Indeed, the incorporation of a partially-flipped classroom decreased the amount of time required for learning and displayed even greater positive outcomes, including improved critical thinking, comprehension and information retention (Gorres-Martens et al., 2016; Khanova et al. 2015b).

Based on the above-mentioned review of literature about the FC advantages and disadvantages, the present short communication adopted an inverted strategy of learning, but with novel modifications of a FC. The idea was to combine an inquirybased learning model with a partially-FC model to create active learners. Inquiry-based teaching involves presentation of a problem statement. Students then gather as much information as possible on the subject and analyze their findings. This analysis is in the form of discussions and projects that require synthesis (Jacot et al., 2014; Pierce and Fox, 2012).Thus, the objectives of the present study were to evaluate the impact of this modified FC educational module on promoting student perceptions and to cope with international accreditation requirements. This aim was reiterated as the Faculty of Pharmacy at Beirut Arab University (BAU) has been facing a challenge to adopt the National Association of Pharmacy Regulatory Authorities (NAPRA) 2014 competencies to achieve standards of patient care, knowledge and research application, communication and education, and intraprofessional collaboration (http://napra.ca/) to attain its international accreditation. Indeed, the Faculty of Pharmacy has already been successfully accredited (2015-2017) by the Canadian Council for Accreditation of Pharmacy Programs (CCAPP) for its Bachelor of Pharmacy program (http://ccappaccredit.ca/international-programs/list-of-internationalprograms/).

\section{METHODS \\ Design (Framework)}

The course instructor (A.G.) adopted an educational FCinquiry model in the integrated Pharmacotherapeutics course of the academic year 2014-2015. The course under study is a onesemester integrated Pharmacotherapeutics course that included 102 undergraduate students of the $5^{\text {th }}$ level. The " 5 th level students" are those students in the last year $\left(9^{\text {th }}\right.$ semester) of the 5-year $(10$ semesters) Bachelor of Pharmacy program that comprises 180 credit hours of study. Ethical approval status was exempt from review by the Institutional Review Board of BAU.The study plan is carefully designed to meet the educational outcomes identified by the Association of Faculties of Pharmacy of Canada (AFPC) for the respective degree (http://www.afpc.info/). This Pharmacotherapeutics course has 3 credit hours and is delivered once weekly by the same instructor along the whole 15 weeks of the fall semester. This course covers the pharmacotherapeutics practice of cardiovascular disorders in vertical integration with previous pharmacology and pharmacy practice courses, and horizontal integration with professional pharmacy practice hospital rotations. For each class session, a group of 5-10 students was provided with a specific pre-class topic, relevant questions, learning objectives, and interactive learning case studies at least 7 days in advance of in-class time. At the beginning of the course, students met in a discussion and formed groups. Each group selected a topic of interest. The group was then responsible for researching the topics and presenting the materials to peers for discussion during the next class session. In addition, weekly case studies were prepared by the instructor to align with the presented topic and the foundational topic delivered by the instructor the week before. These case studies were presented in form by students and were used to develop their formative assessments. This prepared students for the final summative assessments. Briefly, the teaching paradigm consisted of a pre-class orientation during introductory discussions followed by a mixture of faculty- 
guided materials to review and student self-discovery. In-class didactic conventional lecture about foundational curricular topics were followed next week by flipped student-presentations about the flippable rest of topics. Finally, conventional mini-lecture by instructor reinforced student presentation objectives.

\section{A. Pre-class activities}

Introductory discussions

The goal of these discussions was to engage students in the process of active learning in order to improve accountability and performance. This orientation occurred in person at the beginning of the course and enabled students to actively and deliberately choose the topic and learning objectives most interesting to them from a list of relevant cardiovascular topics. In addition, each student also chose the group based on the chosen topics. Each group's role was to research, discuss, and create a presentation for the larger group on the topic. As guided by the instructor, each group-presented presentation consisted of a definition of the cardiovascular disorder, clinical presentation, management goals, approach, non-pharmacologic, pharmacologic, guidelines, algorithms, monitoring, and references obtained from AccessPharmacy database. Finally, the relevant international guidelines for the management of the selected cardiovascular disorder were recommended to each group specifically based on their skills and knowledge from previous integrated pharmacy practice courses on researching drug information (Amin and Fattouh, 2017). Thus, all the students presented clinical practice guidelines based on randomized controlled clinical trials, systematic reviews, and meta-analyses as facilitated by the instructor (Ghoneim et al., 2016; Hammoud and Ghoneim, 2016).

\section{Preliminary readings}

Book chapters and evidence-based journal review articles of varying complexity were available at the Faculty library to support and expand upon the content of introductory discussions.

\section{Online resources}

Electronic library internet resources of the Access Pharmacy database (http://accesspharmacy.mhmedical.com/index.aspx) were accessed by the students through their university accounts. The AccessPharmacy database is a regularly updated online pharmacy education and practice resource that provides leading pharmacy references for searching curricular topics, researching drugs, and keeping up with the latest pharmacy news. It also helps students develop key decision-making skills with virtual cases, integrated case studies, and care plans. It also contains evidence-based online readings, multimedia videos, animations, and interactive guides. Students were only provided a guided list of topics with relevant questions and clinical cases, and they were instructed to search AccessPharmacy for resources related to their selected class topic.

\section{Online free videos and reliable web links}

Students could access a variety of YouTube videos illustrating some course contents. In addition, instructors provided a guided-list of web links to international guidelines by reputable associations and societies for the management of cardiovascular disorders.

\section{Question and answer sessions}

The instructor was available to answer student questions submitted through the university on-line learning management system, official emails, and at office during the announced office hours prior to class, as an opportunity to assess individual student knowledge gaps and adjust the pre- and in- class activities.

\section{B. In-class activities}

\section{Group presentations}

Groups developed 30-45 minute presentations on preclass assigned specific topics and questions. Students' reading, writing and presentation skills, as well as, the ability to educate evidence to peers were developed. The presenting groups developed writing skills through delivering a written summarized report about the topic they presented to be kept in the course file. This report was also guided and evaluated by the instructor as a post-class activity. Theses presentations might be considered a "flipped-lecture" by the presenting students and a traditional one by the receiving students.

\section{Drug information resource appraisal}

Students reviewed and critiqued the selected journal articles and websites focusing on current pharmacotherapeutics content presented.

\section{In-class oral quizzes and formative assessments}

Short oral quizzes to assess presenting students' knowledge of the specific content area. This also served as formative assessments for the rest of attending class audience students including also the opportunity for correction. Frequent quizzes provided all students and faculty with immediate feedback and identified existing knowledge gaps.

\section{Assessments of interactive learning case studies}

Assessments took place after presenting students were guided in the pre-class activities to study specific clinical case scenarios providing opportunities to analyze and synthesize information within the context of patient care simulations. These presenting students then discussed in-class the case and topic with the other students and instructor. Results were shared among groups and answers were critically reviewed by the instructor for a summative assessment of the presenters, and as a formative assessment for the rest of the student audience who asked and discussed answers with the presenting group. Students obtained practice in responding to corrective feedback and provided rationale for clinical judgment with special focus on promoting students' academic integrity in alignment with the University code of ethics, AFPC outcomes and NAPRA competencies. 


\section{Mini lectures}

Maximum length of each about 10-15 min were delivered by the instructor to reinforce objectives and to summarize the main concepts of each presented topic and its evidence-informed decisions for management.

\section{Traditional didactic lectures}

Maximum length of each about 60-75 min were delivered by the instructor at the beginning of each session to cover the main cardiovascular topics that represented the foundation (hypertension, dyslipidemia, angina, heart failure, etc.) for the rest of flippable topics (myocardial infarction, stroke, venous thromboembolism, cardiogenic shock, etc.) that were distributed among the student groups. This means that about half of the curricular topics that represent the foundational ones were traditionally taught in a non-flipped format. However, the rest of the flippable course topics were those that were distributed among the student groups to be actively learnt in a flipped model to save time for attainment of the previously-listed higher intended learning outcomes and competencies within a frame of problembased learning orientation. Each foundational topic was mostly delivered by the instructor one week before the corresponding flippable topic to be better prepared and presented by the student group in the following week along the semester.

\section{Summative assessment}

Evaluations to measure all the students' understanding of traditional didactic lectures and of some selected topics among those presented in a midterm $\left(7^{\text {th }}\right.$ week) and final $\left(15^{\text {th }}\right.$ week $)$ written high-stake exams.

\section{Student Evaluations}

Students' perceptions of this modified FC experience were surveyed. Both anonymous and elective evaluation forms for the Pharmacotherapeutics Fall 2014/2015 course. Additional voluntary feedback items were also collected. A 5-question Likert scale instrument (strongly agree, agree, neutral, disagree, and strongly disagree) was used to evaluate student perception. The questions used on the survey investigated reference availability, teaching hours, assessment methods, active learning and critical thinking. The survey instrument was run online using the student university accounts and was available for a 2 -week period before the final examination. The survey response rate (agree and strongly agree) was represented in percentages based on raw scores in each category along with the corresponding response of the faculty members responsible for the course development. These responsible faculty members were the course instructor and the dean of the faculty. Additional qualitative in-class-solicited voluntary feedback from student comments sent via email to the course instructor was also collected and paraphrased using similar keywords. Items were voluntarily listed as free open comments by interesting students $(\mathrm{n}=10)$ and not designed previously as determined survey questions for response.

\section{Limitations}

This inquiry-based FC was not compared to a traditional instructor-based classroom because this pharmacotherapeutics course was also delivered last year in a partially-flipped format not a traditional didactic (non-flipped) one. The collection instruments, though qualitative, were voluntary, which may have lowered response rate and skewed whole class opinion, nevertheless, this was essential to getting an unbiased response that may result from forcing the students to evaluate forms compulsorily. Study results represent preliminary findings to be published as short communication that reports anonymous and elective student evaluations of the course. In addition, as a qualitative case studyit succeeded in raising questions about how to improve instruction and student engagement. It is noteworthy to mention that, this course, along with other pharmacotherapeutics courses, began to be implemented within our Faculty's new curriculum within the past few years. The delivery style in these courses was transformed over subsequent years from instructorcentered to more active, more student-centered formats.

\section{RESULTS AND DISCUSSION}

Student evaluation forms items of the Pharmacotherapeutics course are presented in table 1 as $\%$ of satisfied students. Eighty-eight percent of the students (as highest percentage) expressed satisfaction with the availability of relevant leading references. The majority ( $81 \%$ and $73 \%$, respectively) was satisfied with their acquisition of critical thinking and problem-solving skills (see Table 1). In addition, 84\% considered the methods of assessment (written - clinical - oral) fair and adequate aligning with the required competencies. Another benefit notes is that $64 \%$ of the students estimated the number of teaching hours sufficient to cover all course items. This reduction in learning time may be an indication of a partial success of the adapted partially-flipped inquiry learning model, which has been a common complaint with a standard flipped learning model(GorresMartens et al., 2016; Khanova et al. 2015a; Khanova et al. 2015b). In addition, a voluntary narrative feedback from a limited number of interested students who wished to evaluate this modified FC experience was paraphrased as general open comments freely listed by studentsas shown in table 2 (not designed previously as determined survey questions for response). Most of students who voluntarily commented stated attainment of better time management, stress management, and self-confidence in preparation to patient care provision. Nearly half of the students also perceived an enhancement of their research and education competencies, intra-professional cooperation, as well as, communication and presentation skills. However, the majority of those who voluntarily commented about the adapted teaching methodology complained of the low-quality presentations of some of their peers. 
Table 1: Student evaluation of the Pharmacotherapeutics course

\begin{tabular}{lc}
\hline Student evaluation item & \% of satisfied students $^{*}$ \\
\hline Necessary references were available & 88 \\
Number of teaching hours were sufficient to cover all course items & 64 \\
The methods of assessment (written - clinical - oral) were fair and adequate & 84 \\
Students were encouraged to discuss and think critically & 81 \\
Topics covered helped develop cognitive, professional, and problem-solving skills & 73 \\
\hline
\end{tabular}

FC: flipped classroom. ${ }^{*}$ Number of responding students is 17-21 out of 102 total class enrollments. A 5-point Likert scale (strongly disagree, disagree, neutral, agree, strongly agree) was used. The survey satisfaction response rate (agree and strongly agree) was represented in percentages

Table 2: Voluntary feedback of students about the modified Pharmacotherapeutics FC experience

\begin{tabular}{|c|c|}
\hline Paraphrased comment item $^{*}$ & \# of students s $^{\#}$ \\
\hline \multicolumn{2}{|l|}{ Satisfying items } \\
\hline Enhanced time management, stress management and self-confidence in patient care & 8 \\
\hline Enhanced communication and presentation skills & 6 \\
\hline $\begin{array}{l}\text { Enhanced data collection, evaluation, evidence-informed decision making, intra-professional cooperation } \\
\& \text { coordination between team members }\end{array}$ & 6 \\
\hline Developing and encouraging continued life-long learning & 6 \\
\hline Enhanced research and education competencies & 5 \\
\hline \multicolumn{2}{|l|}{ Dissatisfying items } \\
\hline Overload to include these presented topics in the summative assessments & 9 \\
\hline $\begin{array}{l}\text { Some topics were presented by colleagues less clearly, accurately and less organized to be used for } \\
\text { assessments }\end{array}$ & 8 \\
\hline Long presentation times $30-45 \mathrm{~min}$ & 5 \\
\hline Large number of students per group (5-10) & 3 \\
\hline $\begin{array}{l}\text { Inequality between team members regarding workload, presentation time, questions and discussions by } \\
\text { instructor and rest of audience students }\end{array}$ & 3 \\
\hline Some audience students did not actively participate in the discussions & 3 \\
\hline
\end{tabular}

FC: flipped classroom. "Items were voluntarily listed as free open comments by interesting students ( $\mathrm{n}=10$ ) and not designed previously as determined survey questions for response. " Number of responding students is out of 102 total class enrollments.

The bulk of these students also expressed that they felt overloaded with bulky content on numerous different topics, group assignments, and overwhelming summative written assessments. While active learning and participation through using this model was encouraged, some audience students were not actively involved in discussions as commented by about one third of students involved. The class/observers active participation in the discussions still needs better implementation for an interactive dual learning strategy. Moreover, these commenters believed the presentation times were too long (30-45 $\mathrm{min})$, the number of students per group was too large (5-10/group), and the workload between presenting team members was unequal.

Student perceptions of instructional method and delivery rose once this partially-flipped inquiry teaching model was adopted. The only area of concern for the present students as compared to those of the last year was in the area of sufficient teaching hours (data not shown). This negative perception may have evolved due to vast amounts of information available via the AcccessPharmacy database during the inquiry method and the additional topics added to the summative assessments. Students may feel overwhelmed by the large shift in responsibility for learning large amounts of information compared to previous years. Students also felt overwhelmed by the large group sizes and the inequality in how group work was distributed. Despite this resistance to change, students perceived higher proficiency in many of the adopted NAPRA competencies. This approach was in line with the previous notion that certain courses or topics may be better suited for the FC-inquiry model (Jacot et al., 2014; Khanova et al. 2015a; Khanova et al. 2015b; Wong et al., 2014).However, others demonstrated that the increased pre-class preparation time improves the learning outcomes (Gross et al., 2015). Based on survey results from a semi-FC-Inquiry based course, even greater improvements were found in learning outcomes (Gorres-Martens et al., 2016). The present FC-inquiry model focused on promoting student's accountability and built on previous knowledge and skills by promoting active learning in pre-class activities in line with previous reports (Jacot et al., 2014; Wong et al., 2014). Furthermore, students felt ownership and responsibility through selection of their own groups and topics. This promoted their accountability and performance. Indeed, the conventional FC instructor-based pre-recorded lectures were totally omitted while focusing solely on more active student inquiry. This higher level of active learning was preceded by introductory discussions that might have increased overload since students were required to extend extensive time and effort researching for the most relevant evidence-based pieces of information. On the other hand, this meaningful modification was applied in a partially-flipped teaching model combined with an inquiring learning model not the standard FC model to save time for attainment of the listed higher intended learning outcomes and competencies. Consequently, this modification succeeded in addressing the envisioned (NAPRA) 2014 competencies to standards of patient care, knowledge and 
research application, communication and education, and intraprofessional collaboration (http://napra.ca/). Moreover, the present modification might represent a milestone in the pathway toward the implementation of a pharmacotherapeutics competency-based framework more specific to the Region (Bajis et al., 2016; Amin and Fattouh, 2017).

\section{CONCLUSIONS}

Students were satisfied with this experience from the availability of pharmacotherapy resources to the enhancement of their critical thinking and professional skills. The students perceived improved researching skills, resource appraisal, and peers-teaching competencies; however, they complained about some low-quality presentations, the over-load in assessments, and time shortage. The value of this modified FC-inquiry model adopted was evidenced by the overall positive student perception of this highly active self-learning model independent of passive pre-recorded lectures.

\section{Future recommendations}

As an adaptation future action plan for an improved FCinquiry model, it may be recommended to keep the institutional subscription to essential pharmacy databases such as the AccessPharmacy used in this model. In addition, the therapeutics databases of DynaMed (http://www.dynamed.com/) and UpToDate (http://www.uptodate.com/) may be an asset to the following PharmD graduate program. It is also recommended that this partially-FC-inquiry model might be compared in a future study with a standard fully-FC course.

\section{ACKNOWLEDGEMENT}

The authors would like to thank Prof. Amr El-Adawi, Prof. Naglaa Mashaal, and Prof. Hossam Hamdy at BAU, for their stimulating ideas and productive environment.

\section{REFERENCES}

Access Pharmacy database. McGraw-Hill Global Education
Holdings, http://accesspharmacy.mhmedical.com/index.aspx[Accessed 2 January 2015].

Amin MEK and Fattouh Y. Assessment of a Pharmaceutical Advertisement Analysis Module in a DrugLiterature Evaluation Course.Am J Pharm Educ. 2017; 81(6) Article 112. doi:10.5688/ajpe816112.

Association of Faculties of Pharmacy of Canada (AFPC). Available at: http://www.afpc.info/ [Accessed 23July 2017].

Bajis D, Chaar B, Penm J, Moles R. Competency-based pharmacy education in the Eastern Mediterranean Region-A scoping review. Currents in Pharmacy Teaching and Learning, 2016; 8(3): 401-28. Available at: http://dx.doi.org/10.1016/j.cptl.2016.02.003.

Canadian Council for Accreditation of Pharmacy Programs (CCAPP). Available from: http://ccapp-accredit.ca/internationalprograms/list-of-international-programs/AAccessed 23 July 2017].
Ghoneim AI, El-Mallah AI, El-Lakany AM. Efficacy and Safety of Angiotensin-Based Pharmacotherapy versus Conventional Therapy for the Management of Isolated Systolic Hypertension: A MetaAnalysis of Randomized Controlled Trials. Int J Clin Pharmacol Toxicol, 2016; 5(7): 231-9. Available at: http://dx.doi.org/10.19070/2167-910X1600039

Gorres-Martens BK, Segovia AR, Pfefer MT. Positive outcomes increase over time with the implementation of a semiflipped teaching model. Adv Physiol Educ. 2016; 40(1): 32-7. doi: 10.1152/advan.00034.2015.

Gross D, Pietri ES, Anderson G, Moyano-Camihort K, Graham MJ. Increased Preclass Preparation Underlies Student Outcome Improvement in the Flipped Classroom. CBE Life Sci Educ. 2015; 14(4):ar36. doi: 10.1187/cbe.15-02-0040.

Hammoud S, Ghoneim A. Pharmacogenetics of Thiazide Diuretics: An Update on Inter-individual Variations. Springer Science Reviews. June 2016, Volume 4, Issue 1, pp 15-23. Epub 2016 Feb 22.Available at: http://link.springer.com/article/10.1007/s40362-016$0038-x$.

Hawks SJ. The flipped classroom: now or never? AANA J. 2014 Aug;82(4):264-9.

Institute of Medicine (IOM).Crossing the Quality Chasm: A New Health System for the $21^{\text {st }}$ Century. Washington, DC: National Academies Press; 2001.

Jacot, M. T., Noren, J. and Berge, Z. L. The Flipped Classroom in Training and Development: Fad or the Future? Perf. Improv. 2014; 53: 23-28. doi:10.1002/pfi.21438

Khanova J, Roth MT, Rodgers JE, McLaughlin JE. Student experiences across multiple flipped courses in a single curriculum. Med Educ. 2015a; 49(10):1038-48. doi: 10.1111/medu.12807.

Khanova J, McLaughlin JE, Rhoney DH, Roth MT, Harris S. Student Perceptions of a Flipped Pharmacotherapy Course. Am J Pharm Educ. 2015b; 79(9): Article 140. doi: 10.5688/ajpe799140.

McLaughlin JE, Roth MT, Glatt DM, Gharkholonarehe N, Davidson CA, Griffin LM, Esserman DA, Mumper RJ. The flipped classroom: a course redesign to foster learning and engagement in a health professions school.Acad Med. 2014; 89(2): 236-43.

National Association of Pharmacy Regulatory Authorities (NAPRA).Professional Competencies for Canadian Pharmacists at Entry to Practice,March 2014. Available from: http://napra.ca/Accessed 23 July 2017].

Pierce R, Fox J. Vodcasts and active-learning exercises in a "flipped classroom" model of a renal pharmacotherapy module. Am J Pharm Educ. 2012; 76(10): Article 196.

Sharma N, Lau CS, Doherty I, Harbutt D. How we flipped the medical classroom. Med Teach. 2015; 37(4):327-30. doi: 10.3109/0142159X.2014.923821.

Taylor DC, Hamdy H. Adult learning theories: implications for learning and teaching in medical education: AMEE Guide No. 83. Med Teach. 2013; 35(11):e1561-72.

Wong TH, Ip EJ, Lopes I, Rajagopalan V. Pharmacy students' performance and perceptions in a flipped teaching pilot on cardiac arrhythmias. Am J Pharm Educ. 2014; 78(10): Article 185.

How to cite this article:

Ghoneim A, El-Lakany A. Student Perceptions of a Modified Flipped Classroom Model for Accreditation in a Pharmacotherapeutics Course. J App Pharm Sci, 2017; 7 (11): 015-020. 